\title{
Multiscale integration of satellite, airborne and field data for Mediterranean vegetation studies in the natural area of the Castelporziano Estate (Rome)
}

\author{
Alessia Allegrini $\left({ }^{1}\right)$, Silvia Anselmi $\left({ }^{1}\right)$, Rosa Maria Cavalli $\left({ }^{2}\right)$, Fausto Manes $\left({ }^{1}\right)$ and Stefano Pignatti $\left({ }^{2}\right)\left({ }^{3}\right)$ \\ $\left({ }^{1}\right)$ Dipartimento di Biologia Vegetale, Università degli Studi di Roma «La Sapienza», Roma, Italy \\ $\left(^{2}\right)$ Laboratorio Aereo Ricerche Ambientali (LARA), IIA-CNR, Tor Vergata (RM), Italy \\ $\left(^{3}\right)$ Istituto di Metodologie per l'Analisi Ambientale (IMAA), CNR, Tito Scalo (PZ), Italy
}

\begin{abstract}
A new experimental approach to land analysis has recently been developed, based on the integration of information acquired on different scales; it enables the structure and the functionality of the vegetation in natural ecosystems to be analysed. This research aims at assessing the potentiality of the experimental approach by the integration of airborne and satellite remotely sensed data with ground measurements of structural parameters. In July 1999 a joint campaign for the acquisition of airborne (MIVIS, spatial resolution $3 \mathrm{~m}$ ) and satellite remotely sensed data (Landsat 5TM, spatial resolution $30 \mathrm{~m}$ ) and measures taken at ground (PAI), was deployed in the Presidential Estate at Castelporziano (Rome, Italy). The spectral signatures of the main vegetational types of the Estate were examined and the PAI were related to NDVI values, calculated by means of satellite and airborne images. The adopted approach enabled PAI maps to be produced. The linear relation between measured PAI and estimated PAI showed a higher coefficient of determination when the MIVIS data were used. The sensor high spectral resolution has moreover allowed to better describe the structural characteristics of the main plant typologies at Castelporziano Estate.
\end{abstract}

Key words MIVIS - Landsat - Plant Area Index (PAI) - down-scaling - Mediterranean vegetation

\section{Introduction}

Studies of remotely sensed images from different platforms can enable the land use of the territory to be classified, and can provide useful elements for the purpose of restoring environmental quality. The analysis of remotely sensed

Mailing address: Dr. Alessia Allegrini, Dipartimento di Biologia Vegetale, Università degli Studi di Roma «La Sapienza», P.le Aldo Moro 5, 00185 Roma, Italy; e-mail: allegri@sun1.fabaris.it images, with the technological progress of sensors, has made it possible to acquire precise territorial information, constituting an important instrument for monitoring the vegetation and for drawing up thematic maps. Moreover, remote sensing is used in territorial planning and in resource management, permitting the analysis of phenomena which could not otherwise be investigated and understood and, above all, it can act as an effective method of control of ecosystem dynamic processes. Furthermore, the study of appropriate remotely sensed green indices yields information on the structural and functional conditions of vegetation affected by natural phenomena (climate, pest attacks, etc.) and/or by anthropic impact (air, water and soil pollution, urban and industrial development, etc.). 
A new experimental approach has recently been developed by means of analyses that integrate the studies of many disciplines on different spatial and temporal scales in order to deepen our knowledge of the structural and functional processes of ecosystems, as well as to predict possible consequences connected with the problem of global change (Manes et al., 1997a).

The analysis of the plant communities in a territory on a structural basis is essential for the characterisation of the processes that regulate their dynamism, due to the profound influence that the structure has on the interactions between vegetation and environment. The structure of a community derives from the architecture of the single individuals composing it and from their competition for light and nutrients: this determines the way in which the individuals arrange themselves in space (Norman and Campbell, 1989).

One of the major characteristics of the structure of a plant formation is the Plant Area Index (PAI), defined as the plant area by ground surface unit. Knowledge of this parameter is critical to be able to estimate many processes, such as the $\mathrm{CO}_{2}$ flux, transpiration, interception of rainfall and dry depositions: all processes closely connected with the leaf area (Chason et al., 1991). Moreover, closely correlated with the PAI is the leaf biomass, whose estimation is required for carbon fixation studies (Burton et al., 1991). PAI, therefore, is a basic attribute of the canopy and its definition is an important factor in establishing the spectral responses of plant formations.

Some authors have correlated PAI data measured in the field with data of indices calculated by means of remotely sensed satellite images (White et al., 1997). This type of approach, apart from providing quantitative information on the development of the plant area per unit of soil surface, makes the spatial representation of this index possible for the plant communities present in a territory, thereby helping to draw up of thematic maps describing the vegetation types and status.

The aim of this paper is to analyse the structural characteristics of vegetation types by airborne hyperspectral MIVIS sensor and contem- porary satellite Landsat 5TM images and evaluate the goodness of PAI values estimated by the two platforms.

\section{Study area}

The Castelporziano Presidential Estate is situated about $20 \mathrm{~km} \mathrm{~S}-\mathrm{W}$ of Rome (fig. 1a). The territory measures approximately 6200 ha. The climate is of Mediterranean type, with modest rainfall irregularly distributed through the year, and drought period that can last even more than 3 months. The Estate is characterised by its very heterogeneous plant types which are, moving inland from the coastline: psammophilous vegetation, maquis coenoses, woods mainly of Quercus ilex $\mathrm{L}$. and woods with a prevalence of deciduous oaks (Manes et al., 1997b).

To describe the area from a naturalistic point of view a supervised classification procedure based on the maximum likelihood method was applied on the Landsat image, to discriminate the main plant typologies (fig. 1b). The resulting classification describes with a good level of confidence all the vegetation types in the Castelporziano Estate with spectral classes as described by the hierarchical type classification system «CORINE Land Cover» (until to 4th level). The plant typologies present in the territory highlight the high naturalistic value of the study site in the coastal territory of Latium (Lucchese and Pignatti, 1990).

The following studies conducted on the PAI parameters focused on the four major vegetation classes representative, from a naturalistic point of view: sclerophyllous vegetation with holm-oak prevailing, reafforestations of Pinus pinea L., mixed woods (holm-oak and pine), deciduous oak forest with Carpinus orientalis Miller, deciduous oak forest with evergreen shrubs (fig. 1c).

\section{Remotely sensed data}

The analysis of the remotely sensed data was conducted on Landsat 5 TM images of 21st July 1999 (frame 191-31) (courtesy of Telespazio SpA) and on 6 MIVIS runs of the even 


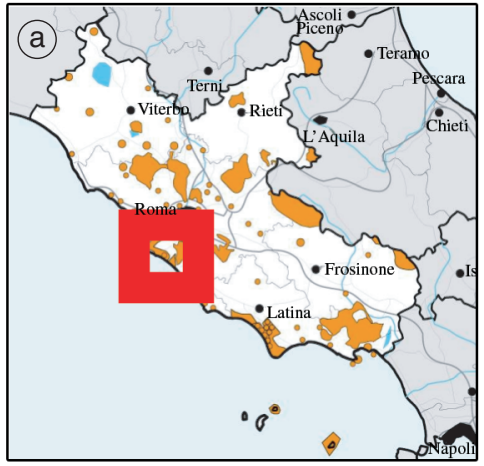

(C)
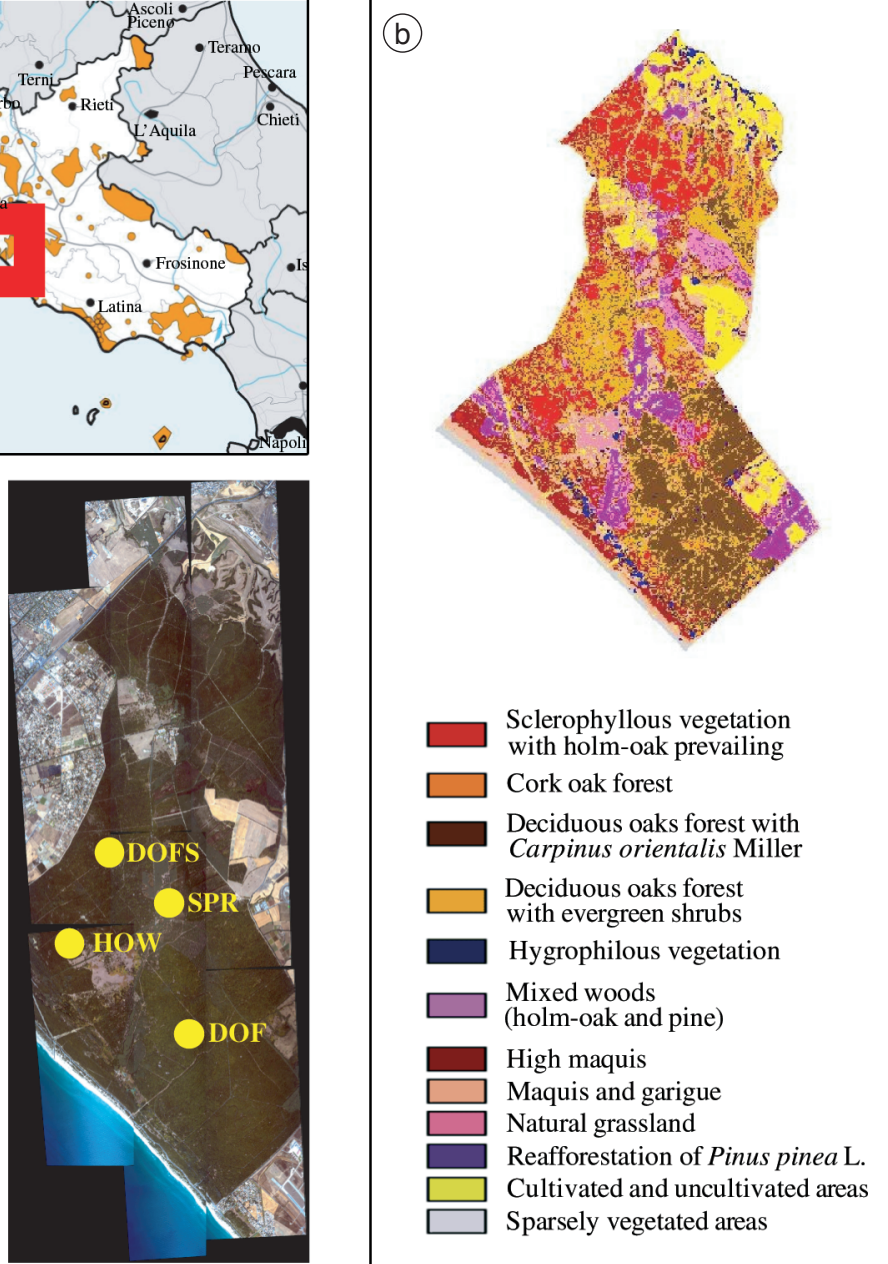

Fig. 1a-c. a) Study area; b) Landsat 5 TM supervised classification; c) runs MIVIS mosaic of the Castelporziano Estate with sample sites.

date acquired at the altitude of $1500 \mathrm{~m}$ a.s.l (3 $\mathrm{m} /$ pixel) using the ILWIS 2.2 and ENVI 3.6 processing software.

The Landsat 5 satellite, in orbit since 1984, is equipped with the Thematic Mapper (TM) sensor, a multispectral scanner able to acquire images in 7 wavelength intervals. Its spatial resolution is $30 \mathrm{~m}(120 \mathrm{~m}$ in thermal infrared wavelength).

The MIVIS (Multispectral Infrared and Visible Imaging Spectrometer) sensor is a Dedalus
AA5000 spectrometer implemented within the LARA project (Laboratorio Aereo Ricerche Ambientali) of the National Research Council Institute for Atmospheric Pollution. It consists of 4 elementary spectrometers which simultaneously register 102 bands: the first spectrometer registers 20 channels in the visible and near infrared region, the second 8 channels in the middle infrared region, the third 64 channels in the short wave infrared and the fourth 10 channels in the thermal infrared region. 
The MIVIS hyperspectral images make it possible to carry out analyses of extreme spatial detail and are very useful above complex areas such as that of the Mediterranean region where human pressure is intense. In particular, airborne hyperspectral data show high diagnostic capabilities in areas of small extent or with considerable territorial fragmentation.

The Landsat TM image was calibrated using the method proposed by Maselli et al. (1998). Landsat and MIVIS images were geometrically corrected using IGMI topographic tables (scale 1:25000) and Regional Technical Map (scale 1:10000) applying the nearest neighbour algorithm during warping. Once radiometrically and geocoded MIVIS runs (pixel geocoding accuracy of $3 \mathrm{~m}$ ) were then mosaicked to obtain an overall view of the Estate.

The Normalized Difference Vegetation Index (NDVI) (Rouse et al., 1974) was calculated on the TM and MIVIS images. The spectral index for the Landsat images was calculated by the relation (TM4-TM3)/(TM4+TM3) while, for MIVIS images, by using channels 12 (653$673 \mathrm{~nm})$ and $20(813-833 \mathrm{~nm})$ respectively corresponding to TM3 and TM4 central wavelength.

\section{Plant area index measurements}

White et al. (2000) stress how instruments based on light transmittance are an optimal experimental approach for the analysis of vegetation related data on a multitemporal basis, and of these the LAI-2000 Plant Canopy Analyser (LI-COR Inc., Nebraska, U.S.A.) seems to provide the most reliable estimates, although some authors point out the need to apply correction factors to obtain quantitative data of Leaf Area Index (LAI), defined as the area of one of the two leaf surfaces by ground surface unit (Chen, 1996; White et al., 1997)

Recently, White et al. (2000) defined more clearly a number of adimensional indices linked with the structure of the plant cover: the Stem Area Index (SAI), defined as the area of one side of the stem by ground surface unit, in which the term «stem» includes dead leaves, branches and trunks; and the PAI, defined as the plant area by ground surface unit, which represents the sum of the SAI and the LAI.

In the summer of 1999 a field campaign was carried out in the Castelporziano Estate to monitor the structural and functional characteristics of the principal plant typologies with the LAI2000 Plant Canopy Analyser. The plant typologies studied are those representative of the Mediterranean vegetation (fig. 1c): sclerophyllous vegetation with holm-oak prevailing, reafforestations of Pinus pinea L., mixed woods (holm-oak and pine), deciduous oak forest with Carpinus orientalis Miller, deciduous oak forest with evergreen shrubs. The relations between measured PAI and NDVI values were performed according to Manes et al. (2001).

\section{Results and disussion}

The MIVIS spectral signatures of the main plant typologies (fig. 2a-d) show the red edge in the near-infrared region (mainly related to internal leaf structure) and at greater wavelengths the absorption peaks related to water present within the leaves. From this graph it is easy to distinguish the different spectral behaviour of the plant typologies in the near-infrared wavelengths like the sclerophyllous communities that show a lower reflectance than broadleaf ones (oak forest fig. 2a-d). Evergreen plant species have leaves with a high degree of sclerophilly, i.e. rich in sclerenchymatic, coriaceous and persistent tissues. The spectral signature of the reforestations of Pinus pinea L. is the lowest within the plant typologies analyzed because the structure of the mesophyll conifers has fewer intercellular spaces where the light is poorly reflected (Knipling, 1967).

The spectral response analysis, performed on Landsat pixels, did not show wide differences between one pixel and ten pixels (data not shown) while the difference of the spectral response of vegetation between a ROI of 1 and 100 pixel was observed. The lowest radiance values observed in the near infrared region, considering areas of $900 \mathrm{~m}^{2}$ (100 pixel) is explained as the effect of the soil on the vegetation spectral response, which induces a lowering of the radiance curve in the spectral signatures. 
(a)

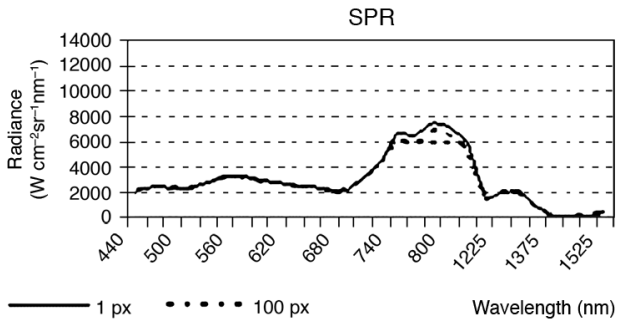

(C)

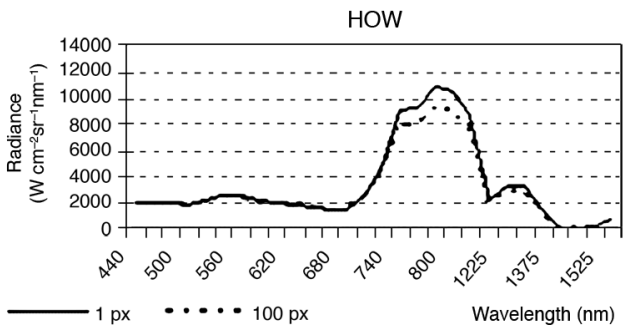

(b)

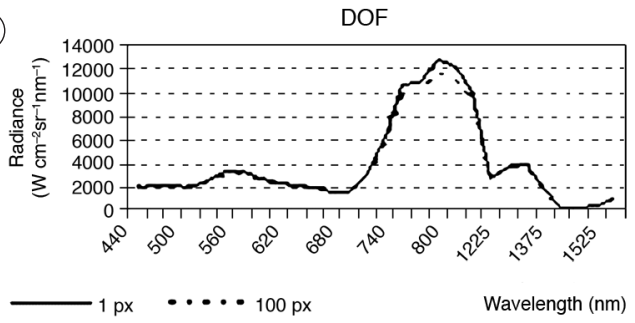

(d)

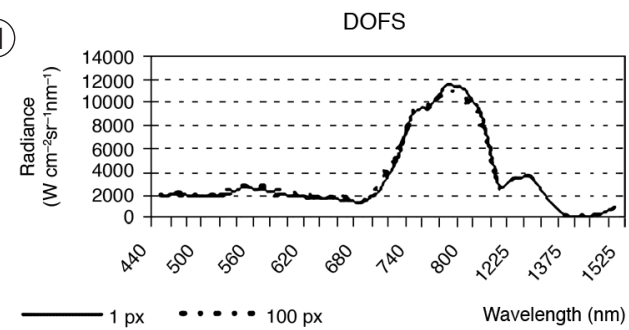

Fig. 2a-d. MIVIS spectral signatures, relative to 1 pixel and 100 pixels areas, of the studied plant typologies: a) reafforestation of Pinus pinea L. (SPR); b) deciduous oak forest with Carpinus orientalis Miller (DOF); c) sclerophyllous vegetation with holm-oak prevailing (HOW); d) deciduous oak forest with evergreen shrubs (DOFS).

(a)

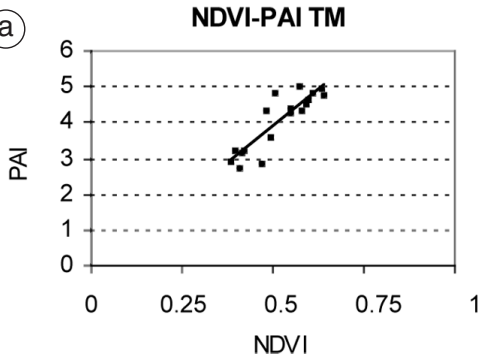

(b)

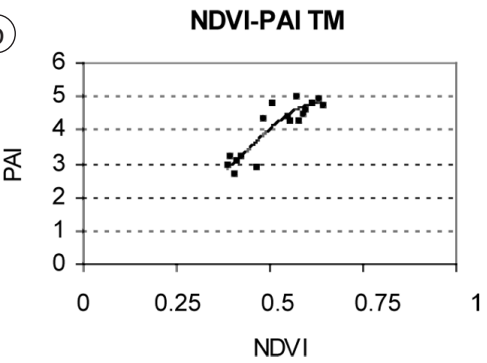

Fig. 3a,b. Linear (a) and cubic polynomial (b) relationships between NDVI values, calculated on the basis of the TM image, and PAI values measured in the field. The coefficient of determination $\left(R^{2}\right)$ equal to 0.79 for the linear relation $(y=8.2782 x-0.2459)$, and to 0.84 for the polynomial relation $\left(y=-124.46 x^{3}+170.14 x^{2}+\right.$ $-66.787 x+10.456)$

The PAI values, measured in the field, vary from a value of 2.69 for the reafforestations of Pinus pinea L., to 4.94 for the deciduous oaks forest with Carpinus orientalis Miller. The pine reafforestations showed PAI values lower than those of the broadleaf species with an equal degree of cover, because of the different architecture of the canopy and of the different leaf morphology (Manes et al., 1997b). The «broadleaf woods with prevalent deciduous oaks» show PAI values in accordance with what is reported by Gower et al. (1999). Moreover the «broadleaf woods with prevalent deciduous oaks with Carpinus orientalis Miller» show higher PAI values than the «broadleaf woods with prevalent deciduous oaks with sclerophyllous understorey», according to Giordano et al. (1996).

Because PAI is a key variable that is functionally linked to the spectral reflectance (Baret and Guyot, 1991), it is well known that the PAI 
is directly correlated with the NDVI, due to the fact that, if the layer of leaves in the canopy increases, the value of reflected radiation in red wavelengths it will decrease, while in near-infrared wavelengths it will increase, raising both indexes (NDVI and PAI). On the basis of this reasoning, it can be stated that the PAI is positively correlated to an increase in the difference between near-infrared and red reflectance (Curran et al., 1992). To determine NDVI by remotely sensed images, the wavelengths relative to red and near infrared regions are used; as already mentioned, the examination of the reflectance of vegetation shows that in the near infrared wavelengths the leaf reflectance is high, while in the red wavelengths absorption by the leaf pigments is high.

The relationships between NDVI values, calculated on the basis of the TM image, and a subset of PAI values (used as controls), measured in the field, were graphed and analysed. The scatterplot of the two indexes brings out linear (to better

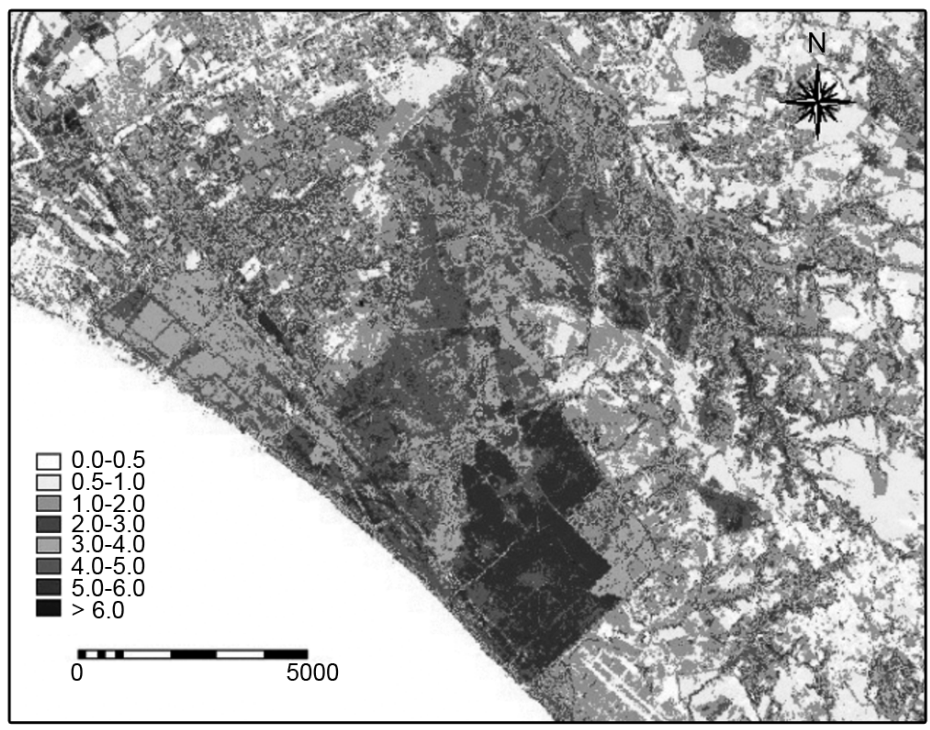

Fig. 4. Plant Area Index map (Landsat 5 TM image of 21 July 1999).
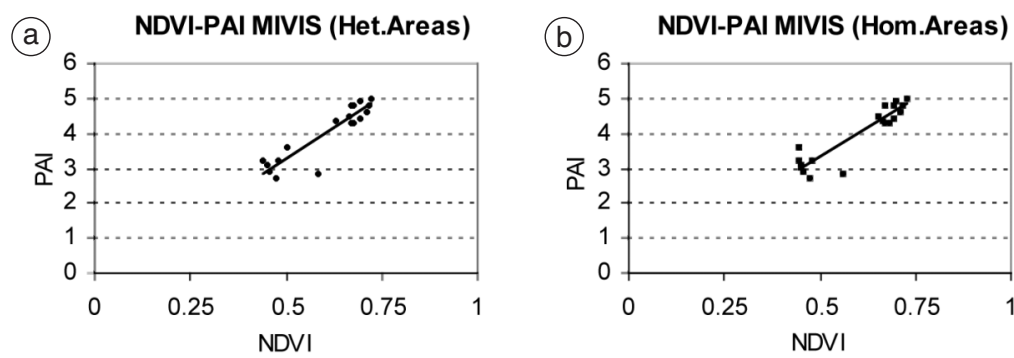

Fig. 5a,b. Linear relationships between NDVI values, calculated on the basis of the MIVIS image, and PAI values measured in the field. The coefficient of determination $\left(R^{2}\right)$ is equal to 0.83 for both a) heterogeneous $(y=6.8851 x-0.1451)$; and $\mathrm{b})$ homogeneous areas $(y=6.5625 x+0.0563)$. 
(a)

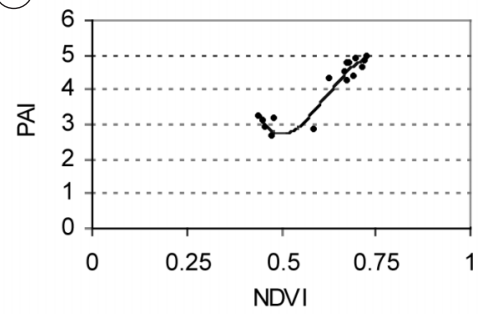

(b)

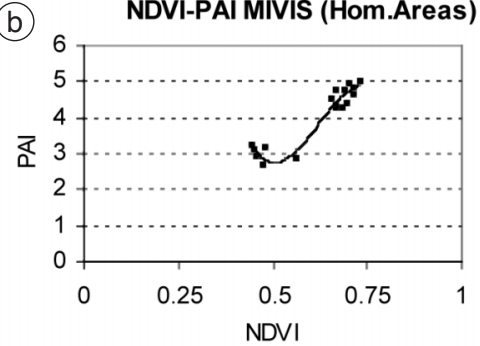

Fig. 6a,b. Cubic polynomial relationships between NDVI values, calculated on the basis of the MIVIS image, and PAI values measured in the field. The coefficient of determination $\left(R^{2}\right)$ is equal to a) 0.91 for the heterogeneous $\left(y=-357.39 x^{3}+661.78 x^{2}-394.36 x+79.122\right)$; and b) 0.94 for the homogeneous areas $\left(y=-329.85 x^{3}+615.12 x^{2}+\right.$ $-368.71 x+74.565)$.

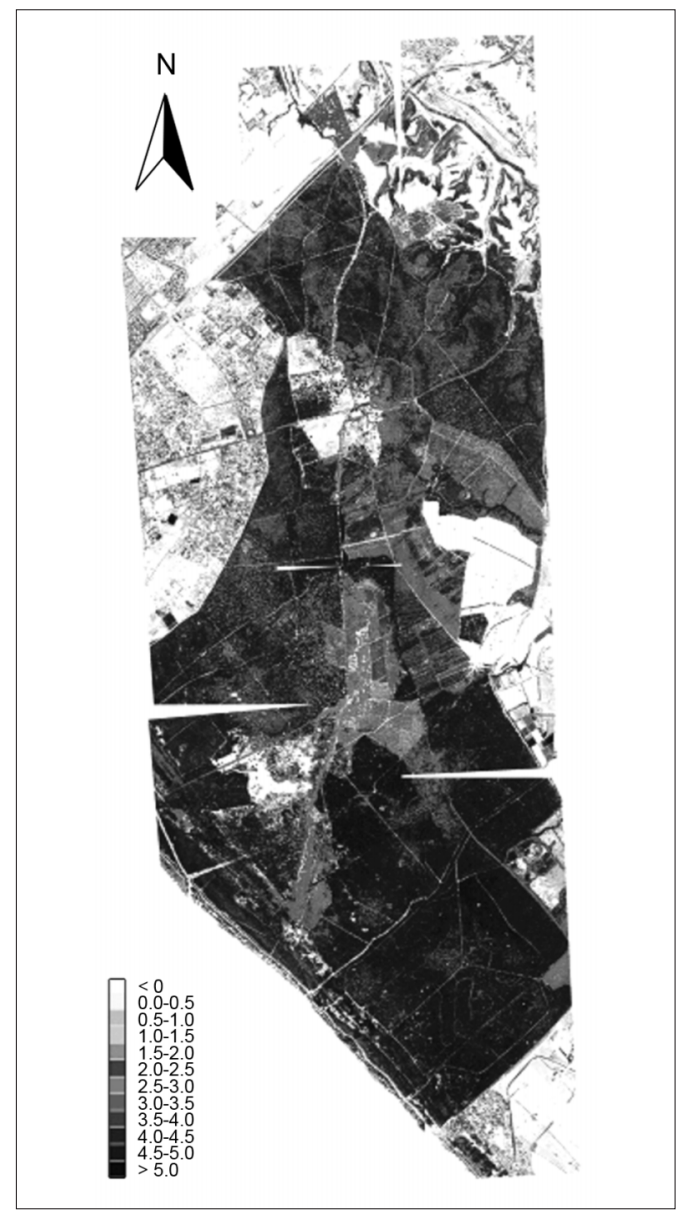

Fig. 7. Plant Area Index map (MIVIS image of 21 July 1999). spatialize the data) and cubic (to better approximate the different species). polynomial relationships, based on 17 PAI measurements and the corresponding 17 NDVI values, obtaining a coefficient of determination $\left(R^{2}\right)$ equal to 0.79 for the linear relation, and to 0.84 for the polynomial relation (fig. 3a,b). By means of the linear function, PAI values for the entire study area were estimated, obtaining the «Plant Area Index map» (fig. 4).

The same relations (linear and cubic polynomial) were analysed for the MIVIS image considering heterogeneous (mix soil and vegetation pixel) and homogeneous areas (figs. $5 \mathrm{a}, \mathrm{b}-6 \mathrm{a}, \mathrm{b})$. The heterogeneous areas were constituted by ROI of 15 pixels, while the homogeneous ROI were obtained removing the mixed pixels or those relating to the ground.

For the linear relations, the $R^{2}$ of both areas is equal to 0.83 , whereas for the cubic polynomial relations an increase of $R^{2}$ from heterogeneous to homogeneous areas ( $R^{2}$ from 0.91 to 0.94 ) is obtained. This variation is mainly related to the approximation of the cubic polynomial curve, that is relative exclusively to the typologies analysed (Turner et al., 1999). Figure 7 depicted the «Plant Area Index map» as derived according to the procedure adopted for the Landsat data, by means of MIVIS NDVI data (homogeneous areas).

In order to validate the relationship between PAI and NDVI shown above, the linear relation between the entire PAI data set measured in the field and those estimated by means of the relation with the NDVI, was determined. The coefficient of determination obtained is equal to 0.77 for the TM data set and to 0.91 for the 

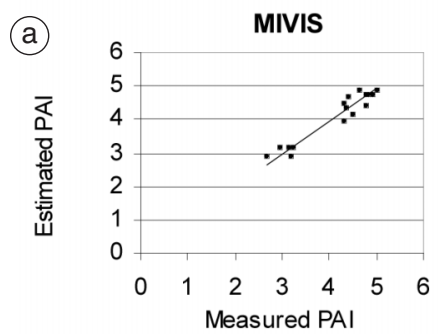

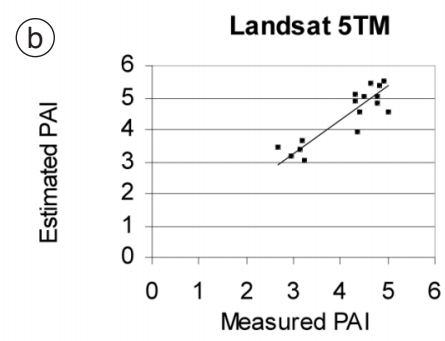

Fig. 8a,b. Linear relationships between PAI measured in the field and PAI estimated by a) MIVIS and b) TM remotely sensed data. The coefficient of determination $\left(R^{2}\right)$ is equal to a) 0.91 for MIVIS data $(y=0.9872 x)$; and b) 0.77 for TM data $(y=1.0711 x)$.

MIVIS data set (fig. 8a,b). The graphs of PAI versus NDVI (figs. 3a,b, 5a,b-6a,b and 8a,b) show how different vegetation types are clustered in two distinct positions along the extremity of the trend lines, therefore it appears evident that discrimination occurs mainly for the broadleaf and coniferous woods.

\section{Conclusions}

The study conducted has stressed the potential of the experimental approach by integration of airborne and satellite remotely sensed data with ground measurements of structural parameters, enabling PAI maps to be produced. In particular, by the assessment of the relations between the field PAI and remote NDVI values, regarding the structural analysis, no sizeable differences emerged comparing the two sensors as both of them have a high degree of significance even though the linear relation between measured PAI and estimated PAI is higher when the MIVIS data were used. The choice of sensor to be used depends mainly on the map plotting scale to be produced. The greater spectral resolution of the MIVIS sensor made it possible to better discriminate and characterise the main plant typologies present in the Castelporziano Estate. For this purpose the ongoing studies on the functional relationships between chlorophyll and wavelength will enable a better evaluation of the differences between sensors spectral resolution in their application to the vegetation environment.

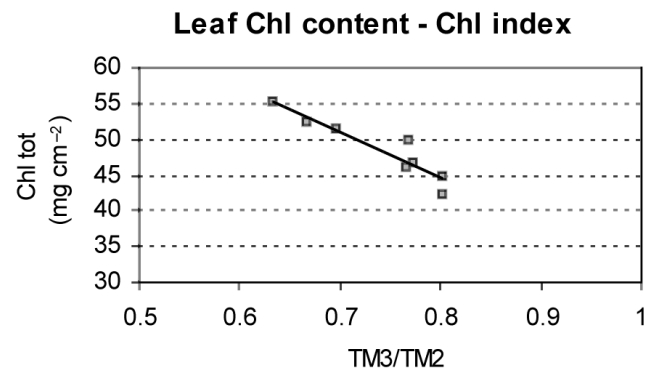

Fig. 9. Linear relationship between «chlorophyll index « (TM3/TM2), calculated on the basis of the TM image, and leaf chlorophyll content. The coefficient of determination $\left(R^{2}\right)$ is equal to $0.87(y=-62.569 x+$ $+94.773)$.

\section{Functional data and future studies on down-scaling approach}

As future studies, we are applying a downscaling approach to MIVIS and TM data as far as chlorophyll content is concerned. Remotely sensed data (Landsat 5 TM image acquired on the 21st July 1999) were processed to obtain a «chlorophyll index» TM3/TM2 (Chappelle et al., 1992). Then field measurements of chlorophyll content on holm-oak leaves (Wellburn, 1994) were carried out in Castelporziano Estate and in other natural and urban green areas (Macchia Grande, Veio, Villa Pamphili, Villa Borghese and Villa Ada) in the metropolitan area of Rome. A relationship between leaf chlorophyll content and «chlorophyll index» values was 
found (fig. 9). The coefficient of determination $\left(R^{2}\right)$ is equal to 0.87 . The same procedure will be adopted for MIVIS datum and then the results will be scaled down.

\section{Acknowledgements}

The authors are grateful to Maurizio Poscolieri for valuable discussions and to Angela Mirabelli for help in improving the paper.

\section{REFERENCES}

BARET, F. and G. Guyot (1991): Potentials and limit of vegetation indices for LAI and APAR assessment, Remote Sensing Environ., 35, 161-173.

Burton, A.J., K.S. Pregitzer and D.D. ReEd (1991): Leaf area and foliar biomass relationships in northern hardwood forests located along an $800 \mathrm{~km}$ acid deposition gradient, For. Sci., 37 (4), 1041-1059.

Chappelle, E.W., M.S. Kim and J.E. McMurtrey (1992): Ratio Analysis of Reflectance Spectra (RARS): An algorithm for the remote estimation of the concentrations of chlorophyll a, chlorophyll b, and carotenoids in soybean leaves, Remote Sensing Environ., 39, 239-247.

Chason, W., D.D. BALdocchi and M.A. Huston (1991): A comparison of direct and indirect methods for estimating forest canopy leaf area, Agri. For. Meteorol., 57, 107-128.

CHEN, J.M. (1996): Optically-based methods for measuring seasonal variation of leaf area index in boreal conifer stands, Agri. For. Meteorol., 80, 135-163.

Curran, P.J., J.L. Dungan, B.A. Macler, S.E. Plummer and D.L. PETERSON (1992): Reflectance spectroscopy of fresh whole leaves for the estimation of chemical concentration, Remote Sensing Environ., 39, 153-166.

Giordano, E., A. Macuz, G. Scarascia Mugnozza and A. TINELLI (1996): Effetto dei fattori ambientali sulla rinnovazione naturale dei querceti caducifogli, in «Progetto di Monitoraggio Ambientale della Tenuta Presidenziale di Castelporziano. Creazione di un Sistema Informativo Territoriale Ambientale Castelporziano (SITAC)», III Seminario Tenuta Presidenziale di Castelporziano, 14 June 1996, 189-196.

Gower, S.T., C.J. KuCHARIK and J.M. Norman (1999): Direct and indirect estimation of Leaf Area Index, $f_{\mathrm{APAR}}$, and Net Primary Production of terrestrial ecosystems, Remote Sensing Environ., 70, 29-51.

KNIPLING, E.B. (1967): Physical and physiological basis for differences in reflectance of healthy and disease plants, in Proceedings of the Workshop on Infrared Color Photography in the Plants Sciences, 2-3 March, Winter Hanven, Florida.

Lucchese, F. and S. Pignatti (1990): Sguardo sulla vegetazione del Lazio marittimo, Accad. Nazionale Lincei, 264, 4-48.

Manes, F., A. Grignetti, A. Tinelli, R. Lenz and P. CicciOLI (1997a): General features of the Castelporziano test site, Atmos. Environ., 31, 19-25.

Manes, F., S. Anselmi, E. Canfora and M. Giannini (1997b): Remote sensing analysis of Mediterranean ecosystem canopies and upscaling studies, in Earth Surface Remote Sensing, 22-25 September 1997, London, SPIE Proc., EUROPTO Ser., 3222, 246-252.

Manes, F., S. Anselmi, M. Giannini and S. Melini (2001): Relationships between Leaf Area Index (LAI) and Vegetation Indices to analyse and monitor Mediterranean ecosystems, in Remote Sensing for Agriculture, Ecosystems and Hydrology II, September 25-29 2000, Barcelona, SPIE Proc., EUROPTO Ser., 4171, 328-335.

Maselli, F., M.A. Gilabert and C. Conese (1998). Integration of high and low resolution NDVI data for monitoring vegetation in Mediterranean environments, $R e$ mote Sensing Environ., 63, 208-218.

Norman, J.M. and G.S. CAMPBell (1989): Canopy structure, in Plant Physiological Ecology: Field methods and Instrumentation, edited by R.W. PEARCY, J.R. Ehleringer, H.A. MoOney and P.W. Rundel (Chapman and Hall Ltd., London), 301-325.

Rouse, J.W., J.A. HaAs, J.A. Schell and D.W. DeERING (1974): Monitoring vegetation systems in the Great Plains with ERTS, in Proceedings of the Third Earth Resource Technology Satellite-1 Symposium, Goddard Space Flight Center, Science and Technical Information Office, NASA, Washington, D.C, NASA SP-351, 309-317.

Turner, D.P., W.B. Cohen, R.E. Kennedy, K.S. FAsSnacht and J.M. BRIGGS (1999): Relationships between Leaf Area Index and Landsat TM Spectral Vegetation Indices across three temperate zone sites, Remote Sensing Environ., 70, 52-68.

Wellburn, A.R. (1994): The Spectral determination of chlorophylls a and $\mathrm{b}$, as well as total carotenoids, using various solvents with spectrophotometers of different resolution, J. Plant Physiol., 144, 307-313.

White, J.D., S.W. Running, R. Nemani, R.E. Keane and K.C. RYAN (1997): Measurement and remote sensing of LAI in Rocky Mountain montane ecosystems, Can. J. For. Res., 27, 1714-1727.

White, M.A., G.P. Asner, R.R. Nemani, J.L. Privette and S.W. RunNING (2000): Measuring fractional cover and leaf area index in arid ecosystems: digital camera, radiation transmittance, and laser altimetry methods, $R e$ mote Sensing Environ., 74, 45-57. 